\title{
ДЕСКРИПТИВНАЯ МОДЕЛЬ СИСТЕМЫ ПОКАЗАТЕЛЕЙ И ПАРАМЕТРОВ ВЕРТИКАЛЬНО ИНТЕГРИРОВАННОЙ СТРУКТУРЫ (ВИС)
}

\author{
(C) 2018 Контаурова Ксения Алексеевна \\ начальник отдела финансового планирования и анализа \\ АО «Научно-производственная корпорация “Уралвагонзавод”» \\ 119049, г. Москва, ул. Большая Якиманка, д. 40. \\ Аспирантка \\ Финансовый университет при Правительстве Российской Федерации \\ 125993, г. Москва, Ленинградский пр-т, д. 49 \\ E-mail:ks.kon@outlook.com
}

Перечень имеющихся моделей, разработанных к настоящему моменту, не позволяет до конца выявлять комплекс проблем операционной деятельности вертикально интегрированной структуры (далее - ВИС). При анализе деятельности ВИС не всегда и/или не в полном объеме принимаются во внимание немонетарные результаты операционной деятельности, не учитывается свободный потенциал и наличие скрытых резервов предприятия. Неповоротливая модель финансовой отчетности не дает ответы на вопросы об эффективности направлений деятельности. В результате отсутствия методов проведения экспертизы ВИС, принимаемые управленческие решения в большей мере основаны на субъективных решениях руководителей. В связи с этим потребность в методах и методических рекомендациях по проведению комплексной экспертизы деятельности ВИС является обоснованной и актуальной. Авторская модель сбалансированной система показателей (далее - ССП) рассматривает операционную деятельность ВИС с точки зрения трех блоков: «Финансы», «Бизнес-процессы управления», «Производство». В каждом блоке выделяется ряд показателей и параметров, позволяющи проводить экспертизу операционной деятельности ВИС и формировать выводы о финансово-экономическом состоянии как ВИС в целом, так и каждого отдельного Общества, входящего в состав интегрированной структуры.

Ключевые слова: дескриптивная модель, показатели и параметры ВИС, система сбалансированных показателей.

Начиная с прошлого столетия, учеными разработаны различные прескриптивные и дескриптивные экономические модели: управления, развития, повышения эффективности работы. Модели применимы в различных секторах экономики: плановой, рыночной. Перечень имеющихся моделей, разработанных к настоящему моменту, не позволяет до конца выявлять комплекс проблем операционной деятельности вертикально интегрированной структуры (далее - ВИС). При анализе деятельности ВИС не всегда и/или не в полном объеме принимаются во внимание немонетарные результаты операционной деятельности, не учитывается свободный потенциал и наличие скрытых резервов предприятия. Неповоротливая модель финансовой отчетности не дает ответы на вопросы об эффективности направлений деятельности. Одним из немаловажных вопросов, является отсутствие комплексной методики экспертизы операционной деятельности ВИС.
Для целей принятия верного управленческого решения существенное значение имеют операционные показатели работы ВИС: структура затрат себестоимости полуфабрикатов и готовой продукции, объем накладных расходов, производительность труда и трудоемкость, удельные капиталовложения и т.д. При этом сопоставление структуры затрат между номенклатурой выпускаемой продукции недостаточно для выявления и оценки наиболее маржинальных направлений деятельности. В ходе поиска вариантов стабилизации экономического состояния ВИС, определение направлений развития предприятия или выявление направлений для повышения эффективности руководству, для принятия взвешенного решения «что делать дальше?» недостаточно проведения анализа себестоимости номенклатуры выпускаемых изделий.

Более того, анализ соотношения структуры затрат выпускаемой продукции сделать технически сложно из-за значительного объема про- 
изводимой номенклатуры. Отсутствие сопоставимости данных приводит к противоречивым выводам. Несмотря на то, что такой подход выдвигается некоторыми экономистами, в реальной действительности он нашел ограниченное применение.

В результате отсутствия методов проведения экспертизы ВИС, принимаемые управленческие решения в большей мере основаны на субъективных решениях руководителей. В связи с этим потребность в методах и методических рекомендациях по проведению комплексной экспертизы деятельности ВИС является обоснованной и актуальной.

Результаты проведения комплексной экспертизы операционной деятельности ВИС являются основой для принятия верных управленческих решений по стабилизации финансово-экономического состояния ВИС и повышения эффективности работы. Специфика проведения оценки операционной деятельности, описываемая автором в статье, рассматривается на примере работы металлургических корпораций, интегрированных на основе технологических процессов производственного цикла от добычи ресурсов до производства готовых изделий из металла.

Комплексная экспертиза деятельности ВИС включает объективный подход на основе количественного и качественного анализа в процессе проведения оценки показателей операционной деятельности ВИС. Учет финансовых и экономических параметров работы должен отражать свершившиеся события, а также перечень показателей операционной деятельности, остающихся за рамками финансовых границ. Этот подход с различных сторон нашел свое отражение в работах экономистов: П. Друкера, Э. Деминга, Л. Мейселя, К. Мак-Нейра, Л.В. Контаровича, Д. Нортона и Р. Каплана и многих других ученых-экономистов. Рассмотрим более подробно экономическую модель «Сбалансированная система показателей» (далее - ССП) Нортона-Каплана, она строится на основе четырех главных составляющих: финансовой, клиентской, внутренних бизнес-процессах, обучении и развитии рисунок 1.

Общая идея ССП основана на целях и будущей стратегии работы корпорации. Для достижения поставленных целей формируются стратегические критерии операционной деятельности ВИС.

Основной упор в ССП уделяется достижению финансовых результатов по средствам контроля показателей деятельности непосредственных исполнителей. Другими словами задача ССП состоит в трансформации миссии компании в конкретные, осязаемые задачи и показатели. При постановке целей соблюдается равновесие между фактически достигнутыми ранее показателями результатов прошлых периодов и будущего роста корпорации. Последовательность составления плана оценки корпорации через ССП строится следующим образом [3]:

1. Четко сформулировать стратегию развития ВИС и перевести ее в плоскость конкретных задач;

2. Установить соответствие между стратегическими целями и показателями их достижения, проинформировать ключевые подразделения компании;
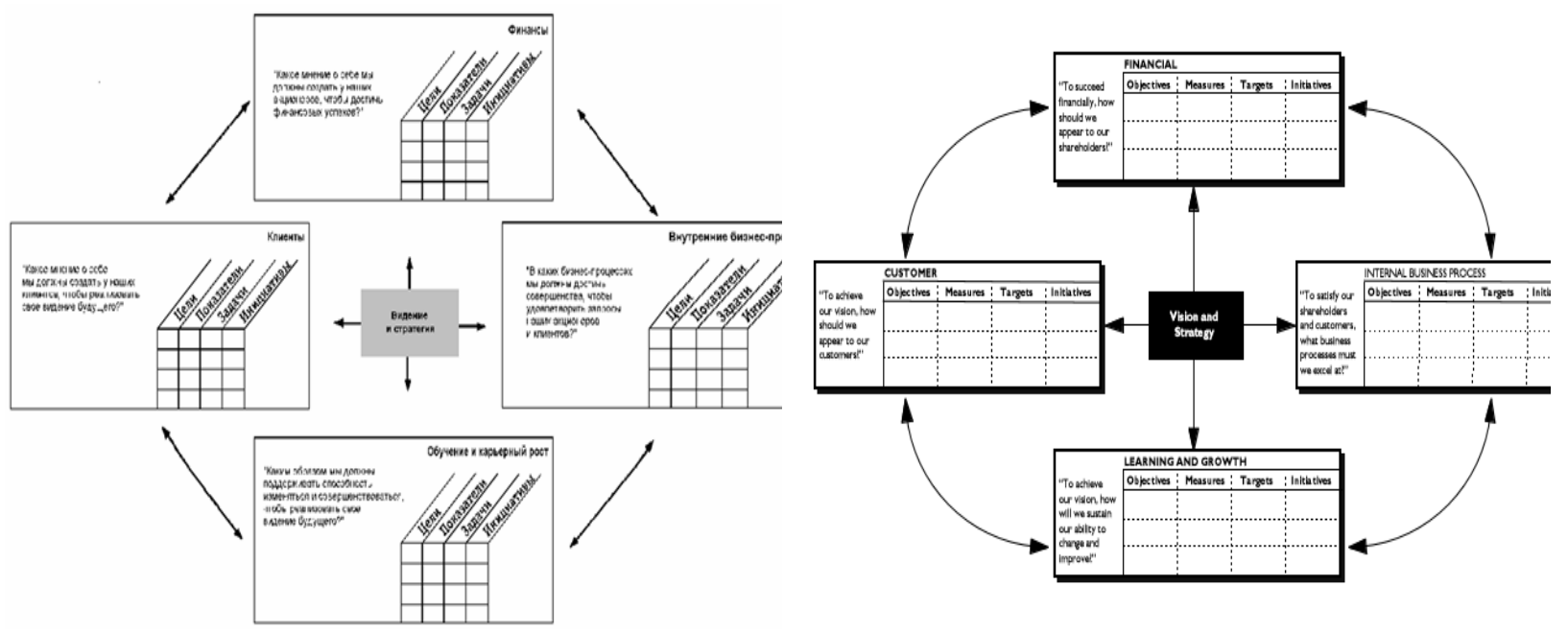

Puc. 1. Сбалансированная система показателей Нортона-Каплана [7] 
3. Запланировать сроки достижения целей и стратегических инициатив;

4. Расширить информационную доступность в достижении поставленных целей и получаемых результатов.

Результатом применения модели ССП является формирование стратегических целей и параметров их достижения по средствам применения карт целей. Карта целей отражает перечень выполнения необходимых задач для достижения каждой цели. Как правило, карты целей сочетают объективные количественные показатели, легко поддающиеся учету с субъективными параметрами будущего роста ВИС. Например, рост чистой прибыли, выручки, увеличение доходности собственного капитала, повышение производительности труда и т.д. Сопоставление показателей ССП с целями стратегии достигается за счет формирования карт целей, охватывающих четыре сферы: финансы, клиенты, внутренние бизнес-процессы, обучение и развитие персонала. Таким образом, каждая стратегическая цель получает описание в виде тактической задачи и программы достижения включенных в карту целей показателей [2].

Однако, достижение показателей стратегии может создать противоречивый эффект. Например, реализация программ повышения качества увеличивает затраты, а целью проектов по оптимизации является снижение расходной части бюджета [1]. Внедрение бережливого производства увеличивает складские мощности цеховых кладовых и время производственного персонала на распределение в них материалов. Строго говоря, при достижении параметров стратегии не всегда учитывается улучшение экономического состояния, и повышение операционной эффективности работы ВИС. Количественные и качественные показатели, характеризующие технологические процессы, движение запасов, обеспечение материальными ресурсами, логистические потоки, уровень подготовки менеджмента, а также качество принимаемых управленческих решений и т.д. требуют вдумчивой комплексной оценки. Безусловно, модель Нортона-Каплана достаточно эффективна для формирования стратегии развития ВИС. Но, не смотря на комплексный подход ССП по достижению стратегических целей предприятия, на наш взгляд модель имеет некоторые недостатки. Применение ССП не достаточно для проведения комплексной экспертизы текущей опера- ционной деятельности ВИС, поэтому в стороне остаются ряд важных не охваченных анализом показателей.

В нашем понимании экспертиза финансово-экономического состояния ВИС гораздо шире по охвату, т.е. предусматривает оценку показателей деятельности всех (большинства ключевых) операционных процессов ВИС. Помимо этого, затруднен фактический поиск вариантов повышения операционной эффективности ВИС. Это вызвано отсутствием понимания в необходимых данных и сложностью в проведении анализа операционных процессов. Отсутствием у персонала навыков и должной квалификации в проведении исследований операционных процессов на основе показателей эффективности в динамике и поиске возможностей повышения эффективности внутренних бизнес-процессов. Одним из наиболее сложных моментов, является отсутствие разработанной модели, методики и методических рекомендаций в проведении комплексной экспертизы операционной деятельности ВИС.

В дополнение к описанным выше проблемам, не нашедшим отражение в модели ССП, необходимо отметить ряд существенных вопросов, сформулированных профессорами д.э.н. А.Н. Романовым и д.э.н. Б.Е. Одинцовым [6]:

- что должно балансироваться ССП?

- каким образом происходит приведение предприятия в сбалансированное состояние в случае его утери?

- каким образом синтезировать цели, представляемые количественными показателями, с целями, представляемыми качественными характеристиками?

Таким образом, мы видим регулярную потребность в комплексной экспертизе результатов деятельности и фактическом анализе эффективности операционных процессов ВИС. В связи с возникшим запросом в проведении экспертизы ВИС необходимо формирование определенного подхода к экспертизе и разработке обоснованной методики проведения анализа финансово-экономического состояния ВИС.

Все обозначенные вопросы требуют изучения и глубоко проработанного подхода для проведения экспертизы текущей деятельности ВИС. При попытке ответить на поставленные вопросы и комплексно оценить деятельность ВИС, мы предлагаем руководствоваться разработанной автором дескриптивной моделью системы по- 
казателей и параметров ВИС (далее - СПП ВИС) для оценки текущего состояния ВИС, модель представлена на рисунке 2.

Предлагаемая автором модель была разработана на основе модели системы сбалансированных показателей (ССП) Нортона-Каплана. На наш взгляд в процессе изучения принципов сбалансированности ВИС найдут отражение иные математические методы и модели.

Современные интегрированные структуры организованы по принципу сложных систем со значительным количеством участников - дочерних обществ (ДО). В рамках применения на практике авторского подхода, разработанной модели СПП, в границах проводимого исследования предлагается рассматривать ВИС, сформированные по принципу технологической интеграции производственных процессов металлургического комплекса.

Ключевая задача моделирования при проведении экспертизы ВИС заключается в упорядоченном получении необходимой информации о работе ВИС для проведения экспертизы операционной деятельности.

Авторская модель СПП рассматривает опе- рационную деятельность ВИС с точки зрения трех блоков: «Финансы», «Бизнес-процессы управления», «Производство». В каждом блоке выделяется ряд показателей и параметров, позволяющих проводить экспертизу операционной деятельности ВИС и формировать выводы о финансово-экономическом состоянии как ВИС в целом, так и каждого отдельного Общества, входящего в состав интегрированной структуры. Разработанная модель СПП ориентирована на экспертизу текущего состояния ВИС, поэтому все денежные потоки при проведении финансового анализа рассматриваются консолидировано. Ключевым принципом разработанной модели СПП для проведения экспертизы ВИС является отражение внутреннего взаимодействия большинства ключевых операционных процессов ВИС и всех входящих в него ДО. Состав блоков предлагаемой к использованию модели СПП, по отношению к базовой модели Нортона-Каплана претерпел существенные изменения, рассмотрим изменения более подробно.

Блок «Финансы» включает весь перечень базовых экономических параметров, отраженных в бухгалтерском учете и отчетности (по факту)

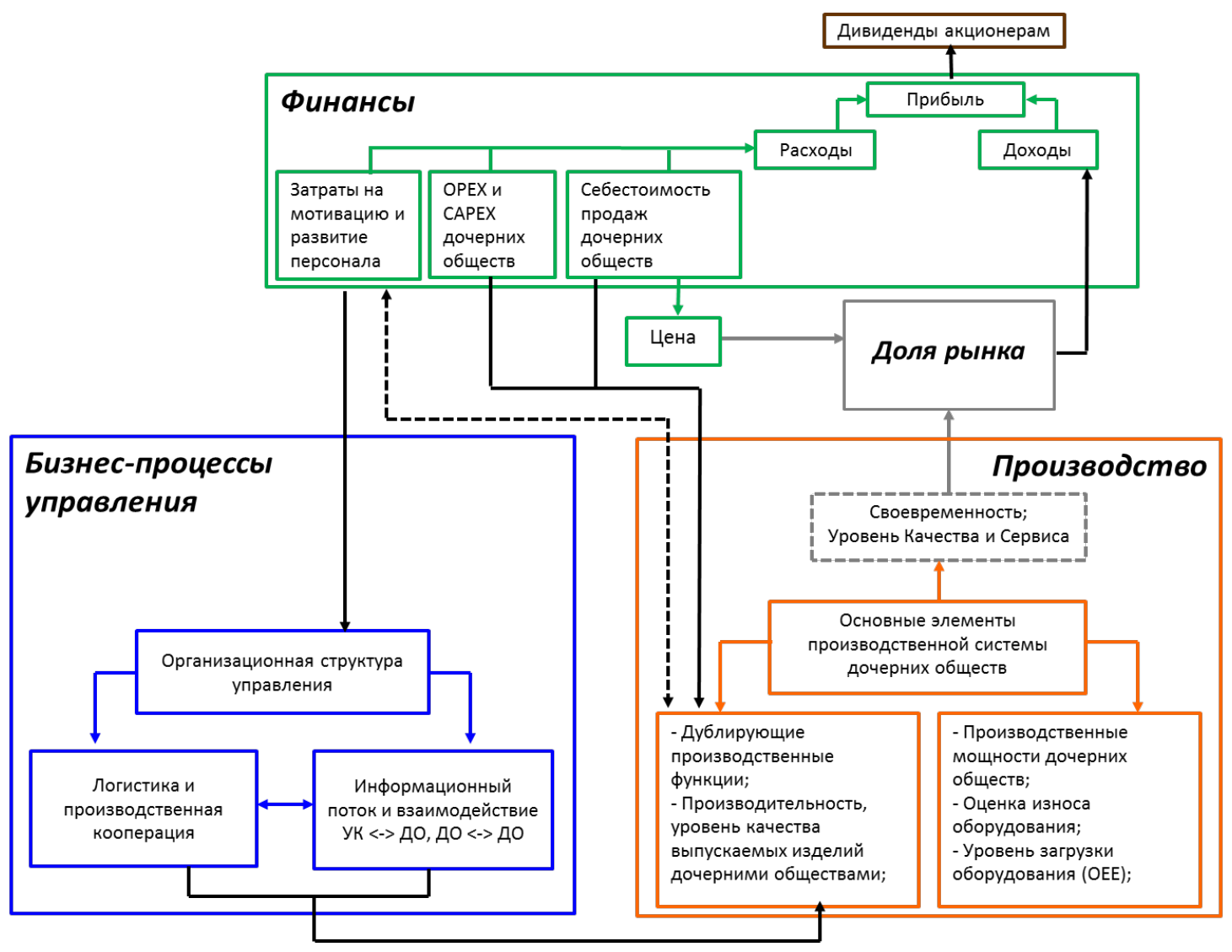

Puc. 2. Дескриптивная модель оценки текущего состояния ВИС 
или бюджетах и прогнозах (по плану). Данный подход является общепринятым во всем мире и достаточно тривиальный. В разработанной модели СПП «Финансовый блок» является генератором денежного потока и эффекта работы ВИС (прибыль/убыток). Экспертиза показателей и параметров финансового блока строится на основе анализа доходной и расходной части отчетности.

Блок «Финансы» содержит два основных элемента: доходы и расходы.

Элемент «доходы», включает показатели: доходную часть (поступления от прочей деятельности, арендные платежи и т.д.). Экспертиза объемов получаемой выручки от реализации учитывает влияние занимаемой доли рынка и уровня установленных цен.

Элемент «расходы» включает перечень ключевых показателей затрат, а именно:

- Затраты на мотивацию и развитие персонала. В предлагаемой к применению модели СПП затраты на персонал являются составным элементом блока «Финансы». Согласно модели Нортона-Каплана затраты на персонал выделены в самостоятельный блок «Обучение и развитие персонала». На наш взгляд долговременный рост и совершенствование развития корпорации обеспечивается высококвалифицированным персоналом, поэтому особенно важно планировать статьи расходов на развитие и удержание персонала. Высокотехнологичное инженерное оборудование не оправдывает себя в случае отсутствия у персонала навыков работы.

Например, механики цеха в силу отсутствия знаний о правилах работы фрезеровочных станков, возможности применения автоматических барабанов производили замену фрез вручную для смены режимов обработки штамповок. Это приводило к увеличению цикла производства деталей, увеличению времени обработки штамповок и снижению производительности станков.

В разработанной модели стрелками обозначены взаимосвязи между элементами входящими в разные блоки. Элемент «Обучение и развитие персонала» имеет прямое влияние и взаимодействие с блоками «Бизнес-процессы управления» и «Производство».

- OРЕХ и САРЕХ ДО - один из материалоемких элементов блока. Объем финансирования затрат на текущие ремонты (OPEX) и инвестиционную деятельность (САРЕХ). Объем осуществляемых фактических (планируемых) затрат на проведение текущих ремонтов прямо пропорционально отражается в структуре затрат себестоимости. Инвестиционные капиталовложения обеспечивают технологическое, инновационное развитие ВИС и отражают степень обновления производственных мощностей и основных фондов интегрированной структуры. Прямое взаимодействие элемента «OPEX и САРЕХ» с элементом «производственные мощности» блока «Производство» позволяет структурировать объем затрат на проведение ремонтов, выявить дублирующие производственные функции. Учет научно-исследовательских и опытно-конструкторских разработок предлагается вести в рамках организации инвестиционной деятельности [4].

- Элемент «Себестоимость продаж» - один из ключевых производственных показателей. Для проведения экспертизы ВИС на основе себестоимости рассчитывается ряд зависимых показателей и параметров. Анализ количественных и качественных параметров структуры себестоимости позволяет выявить резервы повышения эффективности операционной деятельности. Глубокий анализ структуры себестоимости позволяет оценивать роль и качество принятых управленческих решений в каждом ДО. В разработанной дескриптивной модели СПП наглядно показано прямое влияние бизнес-процессов управления и производственных параметров на себестоимость.

Блок «Доля рынка» представляет собой целевой сегмент, в котором на текущий момент проведения экспертизы работает ВИС. Мы считаем, что ВИС влияет на рынок опосредовано и скорее подстраивается под волатильность рыночной среды, нежели наоборот. При этом результатом успешной работы ВИС является положительный эффект экономических выгод, полученный вследствие удовлетворения клиентов. Ключевыми параметрами являются: количество полученных рекламаций, уровень сервиса и обеспечение после продажного обслуживания. Целевой сегмент «Доля рынка» предусматривает экспертизу всех мероприятий ВИС проводимых во внешней среде. Прямое влияние параметров СПП зависит от разработанных и проводимых внутренних мероприятий по улучшению системы качества и своевременности выполнения заказов.

Авторская модель СПП включает концептуально новый блок «Бизнес-процессы управления», позволяющий установить логическую связь и влияние управления на все остальные 
блоки, и их элементы. Блок «Бизнес-процессы управления» предусматривает комплексную оценку операционной деятельности ВИС в разрезе трех элементов:

- организационная структура управления;

- логистика и производственная кооперация;

- информационный поток и взаимодействие УК-ДО, ДО-ДО.

Специфика блока «Бизнес-процессы управления» такова, что все три элемента блока взаимодействуют между собой и оказывают друг на друга прямое влияние. При приведении экспертизы интегрированной структуры результатом отсутствия или неправильно выстроенного информационного потока является дискоммуникация в работе ВИС.

Третий, заключительный блок «Производство» в модели СПП предусматривает проведение анализа по всем элементам производственной системы ДО. В основу анализа блока «Производства» положен показатель производительность труда.

Оценка технологических показателей и параметров работы цехов, оборудования направлена на выявление дублирующих производственных функций, простоев оборудования в результате отсутствия загрузки, проведения ремонтов и износа. Не правильно распределенная загрузка производственных мощностей ведет к срыву сроков выполнения производственной программы. Экспертиза операционной деятельности ВИС блока «Производство» предусматривает рассмотрение количественных и качественных показателей работы цехов.

Например, соблюдение эффективной загрузки производственных мощностей, мониторинг качества выпускаемых полуфабрикатов и готовой продукции, соблюдение плана-графика производства, соблюдение параметров технологического процесса и т.д.

Уровень культуры производства оказывает прямое влияние на объем чистого выпуска полуфабрикатов и готовых изделий, количество возвратного и не возвратного брака, уровень качества товарной продукции.

Разработанная модель СПП дополнена логической связью блока «Финансы» с объемом дивидендов, распределяемых в адрес акционеров.

Как отмечалось выше, авторский подход к проведению экспертизы операционной деятельности ВИС основывается на использовании дескриптивной модели системы показателей и параметров ВИС. Предлагаемая к использованию модель разработана на базе ССП Нортона-Каплана. В известной степени описанный подход к проведению экспертизы операционной деятельности ВИС сходен с мнениями разных экономистов в вопросах оценки корпораций. Поэтому представляется полезным произвести сопоставление моделей (разработанной СПП и ССП Нортона-Каплан) и указать на некоторые принципиальные отличия моделей и особенности предлагаемого авторского подхода проведения экспертизы ВИС.

Первая особенность.

Сущность разработанной модели СПП строится на основе проведения комплексной экспертизы операционной деятельности ВИС и выявления проблем в деятельности интегрированной структуры и входящих в нее ДО. Формирование выводов о работе ВИС в текущий момент времени.

Концепция модели ССП Нортона-Каплана основана достижении баланса системы показателей на основе разработанной стратегии развития. Достижение показателей стратегии ВИС осуществляется за счет формирования задач для каждой цели, обозначенной в стратегии развития ВИС.

Принцип использования ССП является более узким, по сравнению с предлагаемым авторским подходом СПП поскольку в границы стратегии включаются определенные параметры и показатели. Разработанная модель СПП имеет органически связанные элементы и обусловливает оптимальный подход проведения комплексной экспертизы текущей деятельности ВИС. Предлагаемая модель СПП включает оценку количественных и качественных показателей и параметров, относящихся к различным временным периодам, а также рассматриваются в динамике.

Вторая особенность.

Разработанная модель СПП расширяет границы проведения экспертизы операционной деятельности ВИС за счет наличия отдельного блока «бизнес-процессы управления». Анализ эффективности принимаемых решений и качества управления бизнес-процессами ВИС позволяет проводить комплексную экспертизу и отражает влияние качественных показателей и параметров текущей деятельности корпорации.

В модели ССП Нортона-Каплана данный блок не предусмотрен. 
Структура элементов блока «Бизнес-процессы управления» позволяет при оценке операционной деятельности учесть ключевые обстоятельства деятельности ВИС и оценить эффективность принятых руководством решений. Разработанная модель СПП наглядно показывает взаимодействие между управляющей компаний и ДО. Авторская модель отражает потребность в проведении оценки качества организации информационных потоков и уровня взаимодействия между ДО и управляющей компанией. В рамках проведения экспертизы ВИС проводится анализ уровня развития и взаимодействия ДО внутри кооперации.

На наш взгляд существенным фактом отличия СПП от ССП Нортона-Каплана является применение разработанной модели для ВИС, чего нельзя отметить в модели ССП.

Третья особенность.

Комплексная оценка качества управления и процесса принятия управленческих решений блока «Бизнес-процессы управления» представляет сложную проблему, решение которой требует самостоятельного научного исследования. В рамках данной работы мы постарались отразить влияние системы управления на все остальные структурные элементы ВИС. За основу критерия сбалансированности мы предлагаем принимать фактическое/прогнозное значение EBITDA, поскольку данный показатель неразрывно связан с системой производственных и финансовых данных. На наш взгляд, этот показатель аккумулирует действие всей системы управления, то есть учитывает влияние как монетарных, так и немонетарных показателей, что позволяет выявить недостатки управления в системе планирования, фактического учета финансово-экономических показателей, производственно-технологических процессах. Методологиче- ский подход структуризации информационного потока в процессе оценки операционной деятельности был описан ранее [5].

Четвертая особенность.

Визуальная структура разработанной модели была изменена до трех основных блоков «Финансы», «Бизнес-процессы управления» и «Производство». Блок модели ССП «Обучение и карьерный рост», в нашем подходе был включен в модель в качестве элемента структуры затрат и нашел свое отражение в блоке «Финансы». Хотя это преимущество носит не принципиальный, а скорее технический характер, оно все же представляется нам существенным.

Подводя итог выше сказанному, роль разработанной модели СПП для комплексной оценки деятельности ВИС сложно переоценить. Важность оценки качества управления и процесса принятия управленческих решений в системе ВИС априори ясна и является наиболее актуальной в настоящее время. Авторская модель визуально отражает существенное влияние управления на финансовые, технологические и производственные параметры, что требует качественной оценки монетарных и немонетарных показателей в процессе операционной деятельности ВИС. Инерция в связях закостенелой организационной системы свойственна большинству интегрированных корпораций, располагаемых в регионах и моногородах. Недооценка и отрицание возможности применения количественных и качественных показателей в процессе оценки ВИС, несмотря на специфический характер и сложности в проведении экспертизы, может сформировать, как нам кажется, неполное и необъективное представление о характере экономических результатов ВИС в процессе операционной деятельности.

\section{Библиографический список}

1. Беляева И.Ю., Данилова О.В. Обеспечение баланса интересов всех заинтересованных сторон в условиях корпоративной реорганизации // Вестник Университета (Государственный университет управления). 2012. T.№ 9-1. С. 155-161.

2. Григорьева Т.И. Финансовый анализ для менеджеров: оценка, прогноз: учебник. Москва. 2011.460 с.

3. Каплан Р. С., Нортон Д.П. Сбалансированная система показателей от стратегии к действию. Москва. 2003. 241 c.

4. Контаурова К.А. Организация оперативного управления инвестиционной деятельностью крупных корпораций с государственным участием // Экономика и предпринимательство России. 2015. № 12. Ч. 1. С. 760 762. 
5. Контаурова К.А. Модель процесса реструктуризации корпорации с государственным участием, обеспечивающая её стратегию развития// Вестник БИСТ (Башкирского института социальных технологий). 2016. № 4. С. 53-59.

6. Одинцов Б.Е., Романов А.Н. Моделирование процесса приведения предприятия в сбалансированное состояние // Управленческие науки. 2016. С 101-112.

7. Robert S. Kaplan, David P. Norton Linking the Balanced Scorecard to Strategy. California management review vol 39, NO.1, Fall 1996 p. 53-79.

Поступила в редакцию 25.08.2018 